\title{
Dimensões estratégicas da comunicação da ciência
}

\author{
Strategic dimensions of science communication
}

Dimensiones estratégicas de la comunicación de la ciencia

Camila Maciel Campolina Alves Mantovani

- Doutora e mestre em Ciência da Informação pela Universidade Federal de Minas Gerais (UFMG)

- Graduada em Jornalismo pela UFMG

- Professora do Departamento de Comunicação Social da UFMG

- Atuou na Fundação de Amparo à Pesquisa do Estado de Minas Gerais (Fapemig) como bolsista do Programa de Comunicação Científica, Tecnológica e de Inovação (PCCT)

- Desde 1999, trabalha em projetos de pesquisa em novas tecnologias de informação e comunicação com foco nos processos de produção e recepção de conteúdos digitais

- E-mail: camilamm@gmail.com

\section{Verônica Soares da Costa}

- Doutoranda em Textualidades Midiáticas no Programa de Pós-graduação em Comunicação Social da Universidade Federal de Minas Gerais (PPGCOM-UFMG)

- Mestre em História, Política e Bens Culturais pelo Centro de Pesquisa e Documentação da História Contemporânea do Brasil (CPDOC-FGV)

- Especialista em Jornalismo Científico pela Universidade do Vale do Paraíba (Univap)

- Graduada em Jornalismo pela Universidade Federal de Juiz de Fora (UFJF)

- E-mail:ve.scosta@gmail.com 


\section{Resumo}

Caracterizar o público de uma ação comunicacional é fundamental para desenvolver estratégias que atendam às demandas organizacionais, principalmente aquelas relacionadas à percepção de valor de determinada instituição frente a seus interlocutores. A fim de conhecer os públicos do projeto "Minas faz ciência", iniciativa de divulgação científica da Fundação de Amparo à Pesquisa do Estado de Minas Gerais (Fapemig), foi realizada uma pesquisa on-line para coletar dados sobre preferências, hábitos de acesso a informação, bem como o conhecimento dos produtos e serviços desenvolvidos. 0 artigo apresenta as estratégias de pesquisa colocadas em prática, assim como os resultados obtidos e as reflexões acerca das potencialidades e dos desafios da comunicação organizacional no contexto da divulgação científica.

\section{PALAVRAS CHAVE: COMUNICAÇÃO ORGANIZACIONAL・ESTUDOS DE PÚBLICO • DIVULGAÇÃO CIENTÍFICA•FAPEMIG.}

\section{Abstract}

Distinguishing the audience of a communication activity is essential to develop strategies that meet organizational demands, mainly those related to the perceived value of a certain institution before its interlocutors. In order to know the publics of the "Minas faz ciência" project, a science communication initiative undertaken by Fapemig (Fundação de Amparo à Pesquisa do Estado de Minas Gerais), an on-line survey was conducted to collect data on preferences, information access habits, as well as their knowledge about offered products and services. The article presents research strategies put in place, as well as the results and reflections on the strengths and challenges of organizational communication in the context of science communication.

\section{KEYWORDS: ORGANIZATIONAL COMMUNICATION • STUDIES OF THE PUBLIC・SCIENTIFIC COMMUNICATION•FAPEMIG}

\section{Resumen}

Caracterizar al público de una acción de comunicación es esencial para desarrollar estrategias que satisfagan las demandas organizacionales, especialmente los relacionados con la percepción de valor de determinada institución frente a sus interlocutores. Con el fin de conocer a los públicos del proyecto "Minas hace ciencia", iniciativa de comunicación científica de la Fundación de Amparo a la Investigación del Estado de Minas Gerais (Fapemig), se llevó a cabo una encuesta en línea para recopilar datos sobre las preferencias, los hábitos de acceso a la información así como el conocimiento de los productos y servicios desarrollados. El artículo presenta las estrategias de investigación puestos en marcha, así como los resultados obtenidos y las reflexiones sobre el potencial y los desafíos de la comunicación organizacional en el contexto de la divulgación científica. 

a variedade de arranjos possíveis para a divulgação da ciência, da tecnologia e da inovação (CT\&l), encontram-se sujeitos distintos e dispersos, com anseios e necessidades específicas em suas relações com o conhecimento. Nesse contexto, os públicos se colocam como eixo central da divulgação científica: é para eles e a partir deles que as ações mais eficientes de difusão do conhecimento científico devem tomar forma. Entretanto, no dia a dia de trabalho de quem divulga, não são raras as vezes em que surgem perguntas sobre "quem é nosso público" e qual a melhor forma de se comunicar com ele.

Bruce V. Lewenstein (2010) alerta que cada modelo de comunicação da ciência carrega implicações políticas que precisam ser consideradas nas estratégias de divulgação. Assim, se buscamos superar o modelo do déficit 'na comunicação científica, que pressupõe uma sociedade dividida entre especialistas e leigos, é preciso também desenvolver uma nova relação do público com a CT\&I, promovendo trocas de experiências entre cientistas e comunicadores, e considerando também o saber popular.

Para tal, é preciso que o público, em suas variadas configurações, se torne uma interlocutor ativo e participante. Fomentar essa participação, depende, entretanto, de ações anteriores, que englobam o conhecimento da instituição em relação à cultura e aos valores organizacionais que pretende comunicar, bem como a identificação de seus públicos.

Partimos de uma perspectiva da comunicação alinhada ao paradigma da complexidade de Edgar Morin (2011), que indica ser preciso buscar as relações dialógicas, recursivas e hologramáticas a fim de compreender os complexos fenômenos da comunicação em sua configuração contemporânea. Tais relações pressupõem um intercâmbio permanente entre as partes, e entre as partes e o todo, assim como a recursividade dos processos.

Reconhecendo a impossibilidade da totalidade, argumentamos em favor de uma comunicação pública da ciência que se propõe incompleta, mas não por isso menos eficaz. Conforme aponta o autor,

a consciência da multidimensionalidade nos conduz à ideia de que toda visão unidimensional, toda visão especializada, parcelada, é pobre. É preciso que ela seja ligada a outras dimensões (...). Mas, num outro sentido, a consciência da complexidade nos faz compreender que jamais poderemos escapar da incerteza e que jamais poderemos ter um saber total: a totalidade é a não-verdade (MORIN, 2011, p. 69).

Observamos na comunicação institucional, aquela praticada no âmbito das organizações e que visa à complementaridade das estratégias das assessorias, uma audiência já pré-definida pelos interesses da organização. Aqui, trataremos do projeto "Minas faz ciência", iniciativa desenvolvida pela Fundação de Amparo à Pesquisa do Estado de Minas Gerais (Fapemig). Nesse contexto, além dos atores já envolvidos com a produção do conhecimento científico (gestores, cientistas e pesquisadores), existe a demanda e o interesse em atingir públicos para além dos limites dos laboratórios e das paredes dos institutos de pesquisa, a fim de corresponder às demandas de transparência sobre investimentos públicos em CT\&I, entre outros aspectos.

Apresentaremos, portanto, as estratégias utilizadas para conhecer o perfil do público do projeto "Minas faz ciência", e como esse esforço levou a um novo alinhamento das estratégias de comunicação da organização. No contexto de instabilidade e complexidade das organizações, o que se pretendeu foi uma tomada de conhecimento da dinâmica das relações da organização com aqueles que já são afetados por suas ações. Não há dúvidas da importância desse diagnóstico do público como dimensão fundamental para o sucesso das estratégias de comunicação organizacional, e o perfil identificado sinalizou para uma necessidade de adequação das estratégias desenvolvidas com os objetivos que se pretendia atingir.

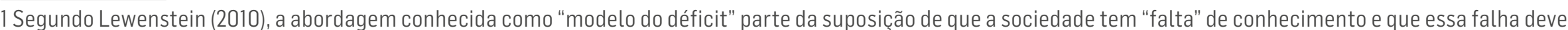

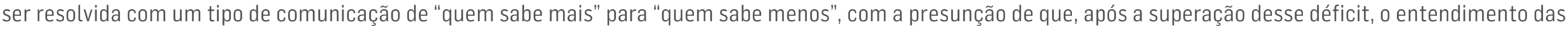
pessoas sobre ciência será "melhor".
} 
A Fapemig foi criada em 28 de agosto de 1985, por meio da Lei Delegada ํㅜ 10. Vinculada à Secretaria de Estado de Ciência, Tecnologia e Ensino Superior (Sectes), tem seus recursos financeiros assegurados pela Constituição Estadual, com a finalidade de induzir e fomentar a pesquisa e a inovação tecnológica de Minas Gerais. Compete à fundação apoiar projetos de natureza científica, tecnológica e de inovação de instituições ou de pesquisadores individuais, que sejam considerados relevantes para o desenvolvimento científico, tecnológico, econômico e social.

Dentre seus eixos de atuação destacam-se a capacitação de recursos humanos para a ciência e tecnologia, por meio de bolsas em diversos níveis de formação; a organização e realização de eventos de caráter científico, tecnológico e de inovação; a realização de intercâmbios entre instituições e pesquisadores brasileiros e estrangeiros; 0 encaminhamento de ações relacionadas à propriedade intelectual e à transferência de tecnologias; a divulgação e disseminação dos resultados de suas atividades e projetos.

No eixo da divulgação, ela mantém o Programa de Comunicação Científica, Tecnológica e de Inovação, também conhecido pela sigla PCCT, coordenado pela Assessoria de Comunicação Social (ACS) e executado com o apoio de um grupo de jornalistas profissionais, que atuam como bolsistas. O PCCT cumpre o papel de desenvolver vocações para a comunicação científica, que resultam em produtos e ações de diferentes naturezas, na mídia impressa e também na internet.

A revista Minas Faz Ciência é o mais antigo e consolidado produto do programa, tendo sido lançada em dezembro de 1999. A publicação é trimestral e conta com uma edição extra anual, de temática especial. São 25 mil exemplares distribuídos gratuitamente para uma base bastante diversa, que inclui moradores de outros estados e regiões do Brasil. Além da revista, o programa mantém um blog ${ }^{2}$, o podcast Ondas da Ciência ${ }^{3}$ e um canal no YouTube chamado Ciência no Ar ${ }^{4}$. Neste artigo, todos esses produtos serão referenciados como "Projeto Minas faz ciência".

Cada um dos produtos é desenvolvido por um ou mais jornalistas da equipe, tendo características específicas de linguagem e abordagem para a divulgação da ciência. Todos utilizam a base de dados de pesquisas financiadas pela fundação para a definição de pautas, mas também podem abordar projetos e ações desvinculados da Fapemig, desde que sejam reconhecidos pelo mérito científico e interesse público. Incluem-se aí pesquisas realizadas por instituições de ensino do estado ou eventos e ações promovidas em âmbito nacional e estadual, como a Semana Nacional de Ciência e Tecnologia, por exemplo, assim como projetos de extensão e outras ações bem-sucedidas de divulgação científica.

0 programa busca não só promover a ciência, mas também discutir os limites e as possibilidades dessa prática. Um dos principais desafios tem sido identificar e caracterizar o público dos produtos com o objetivo de melhor direcionar as ações de comunicação. Sendo um projeto de comunicação pública da ciência, vinculado a uma instituição estadual, é de suma importância que atinja as mais diversas camadas da população, chegando, principalmente, ao público não especializado, conforme mencionado anteriormente.

0 projeto pretende tornar a fundação conhecida por pessoas que não estão envolvidas no ambiente acadêmico, assim como prestar contas dos investimentos financeiros nas pesquisas do estado, dando retorno à população. Para além desses

2 Disponível em <blog.fapemig.br>. Acesso em 4 jul. 2016.

3 Disponível em <https://fapemig.wordpress.com/ondasdaciencia/>. Acesso em 4 jul. 2016.

4 Disponível em <https://www.youtube.com/ciencianoar>. Acesso em 4 jun. 2016. 
objetivos vinculados às políticas de transparência, cabe destacar que a popularização do conhecimento científico assume também papel importante já que, nas sociedades contemporâneas, as questões e controvérsias vinculadas à ciência e à tecnologia permeiam o cotidiano dos cidadãos, exigindo deles algum domínio desses temas.

\section{ORGANIZACẼ̃O COMUNICADA, COMUNICANTE E FALADA}

Os estudos de audiência têm se valido, ao longo dos anos, de diversas abordagens de pesquisa para melhor compreender o comportamento de seu público-alvo. Durante algum tempo, as discussões em torno do tema se davam de maneira compartimentada, tendo por base os elementos constitutivos dos processos comunicacionais, a saber: "produtores, textos e receptores - e momentos - produção, circulação e recepção/consumo" (ESCOSTEGUY, 2007).

Todos esses elementos, que integram o processo em sua totalidade, eram estudados parcialmente, gerando uma visão fragmentada e também reducionista do fenômeno. Da teoria da informação (década de 1950), passando pelos estudos culturais (final dos anos 1970), até chegar aos dias atuais, o que se percebe, nos estudos de recepção, é a busca por incorporar não apenas as dimensões relativas à mensagem - forma e conteúdo -, mas também os aspectos sociais e culturais presentes no processo comunicacional.

Atualmente, a presença das tecnologias nos processos de comunicação tem possibilitado o surgimento de abordagens de pesquisa que se valem da presença das organizações e de seus conteúdos nos ambientes digitais para conduzir seus estudos de público. Algumas metodologias contemporâneas abrangem desde os estudos de usabilidade até as netnografias e as análises de redes sociais. No que concerne ao digital, o que importa destacar é que, já há algum tempo, ele não é mais um território tão distanciado do real. A realidade híbrida, que mescla camadas do digital com camadas do real, criando um espaço chamado por alguns autores (como Lev Manovich, 2006) de espaço aumentado, traz desafios para abordagens de pesquisa tradicionais, que focam nos contextos on e offline de maneira separada.

Sendo assim, o que buscamos neste estudo foi trabalhar esses contextos "distintos" de maneira integrada, percebendo e analisando as interseções entre eles. 0 principal aspecto a ser destacado é o fato de a experiência do sujeito/ usuário/leitor se tornar mais central para o processo de criação dos produtos, conteúdos e/ou serviços, adquirindo uma dimensão estratégica para a organização.

Nesse sentido, o público, que se colocava como parte de um processo, passa a ter uma presença mais constante e estratégica para as organizações. Diante de contextos midiatizados, as questões da comunicação organizacional não se relacionam apenas com o produto em si, mas com as diversas interfaces através das quais o sujeito entra em contato com a marca/ organização/produto/serviço. Há que se ter em mente também as conversações cotidianas que acontecem fora dos canais "controlados" pela organização, mas que impactam a imagem e percepção pública da organização.

No caso aqui apresentado, identificar e conhecer o público dos produtos oferecidos pelo "Projeto Minas faz ciência" permitiu não apenas desenvolver estratégias para oferecer conteúdos mais sintonizados com as necessidades desses interlocutores, como também refletir sobre a organização em um aspecto mais amplo, tendo em vista os valores e 0 diferencial que ela procura entregar aos seus públicos. 
Ao se tornar parte desse processo, o público passa a ter uma presença mais constante e estratégica para as organizações. Isso permite à organização obter informações ou indicações sobre a qualidade da experiência do usuário ao interagir com o que ela tem a oferecer, o que leva a uma maior conscientização sobre os processos e as estratégias de comunicação organizacional, bem como sobre as implicações e os resultados de determinado produto/conteúdo/serviço a ser desenvolvido (FREIRE, 2009).

No entanto, a adoção dessa perspectiva só é possível no momento em que as organizações assumem para si a dimensão da complexidade. Sob essa perspectiva, a comunicação pode ser entendida a partir de três princípios descritos por Morin (2011): o dialógico, que permite manter a dualidade no seio da unidade, em um intercâmbio permanente entre as partes; a recursão organizacional, em que "tudo o que é produzido volta-se sobre o que o produz" (MORIN, 2011, p. 74); e o hologramático, que promove um entendimento das partes contidas no todo a partir do todo que contém as partes, simultaneamente.

0 autor defende que "o pensamento da complexidade tem necessidade da integração do observador e do conceptor em sua observação e em sua concepção" (Morin, 201, p. 76), de modo que essa perspectiva se torna importante instrumento para a análise dos dados coletados na pesquisa apresentada a seguir. A identificação de perfil proposta a partir da coleta de informações não se esgota como instrumento de desenvolvimento de estratégias organizacionais, mas amplia-se a partir do reconhecimento da ação do público-alvo na determinação das ações da instituição.

Rudimar Baldissera (2009) já havia proposto uma leitura da comunicação organizacional a partir dessa perspectiva, de modo que o campo fosse entendido como uma arena de processos e disputas de sentido. Das três dimensões por ele propostas (organização comunicada, comunicante e falada), interessa-nos identificar a terceira, que emerge das respostas obtidas no questionário e que não necessariamente condiz com as motivações iniciais do planejamento estratégico da organização. "Trata-se dos processos de comunicação informal indiretos: aqueles que se realizam fora do âmbito organizacional e que dizem respeito à organização" (BALDISSERA, 2009, p. 119).

Embora nem sempre essa dimensão esteja circunscrita em instâncias de ação da organização, de modo que se estabeleça um controle direto sobre tais processos, concordamos que "à medida que se tornam visíveis e forem identificadas por elas, é possível que exijam algum tipo de investimento em ações e/ou comunicação formal para neutralizá-los, se for o caso" (BALDISSERA, 2009, p. 119). Assim, a coleta de dados por meio de questionário on-line se configura como uma ação estratégica na tentativa não só de identificar o perfil do público, mas também de alcançar a dimensão da comunicação falada que nem sempre é monitorada pela organização.

\section{ESTRUTURAÇ̃̃O DA PESQUISA ON-LINEE DADOS COLETADOS}

A coleta de dados sobre o perfil do público do projeto teve início em 13 de novembro de 2014, com a publicação de um post $^{5}$ no blog Minas Faz Ciência e disponibilização do formulário online previamente construído na ferramenta gratuita Typeforme ${ }^{6}$. 0 texto de apresentação explicitava que o questionário tinha por objetivo conhecer os hábitos do público em relação à busca e ao consumo de informações referentes a ciência e tecnologia de modo que, a partir dos dados obtidos, a Fapemig pudesse discutir e trabalhar definições de estratégias de comunicação e divulgação científicas, visando à melhoria dos processos e produtos já existentes, bem como à criação de novas propostas. 


\section{ANO 13 • NÚMERO 25 • 2 SEM. 2016 - ORGANICOM}

DIMENSÕES ESTRATÉGICAS DA COMUNICAÇÃO DA CIÊNCIA

A pesquisa consistiu de 23 questões, tendo 5 sido abertas, 13 de múltipla escolha e 5 com respostas sim/não. 0 formulário ficou disponível ao público até o dia 21 de fevereiro de 2015 e, além do link no blog, também foi divulgado por meio dos perfis do projeto no Facebook ${ }^{7}$ e no Twitter ${ }^{8}$, em mais de uma publicação. 0 site e as redes sociais digitais da Fapemig (Facebook ${ }^{9}$ e Twitter $^{10}$ ) também foram utilizados para a divulgação e disseminação do link do questionário, assim como 0 mailing da fundação, que contava, à época, com cerca de 5 mil e-mails cadastrados.

Cabe destacar que o público investigado esteve restrito àqueles indivíduos que já circulam pelos canais de comunicação da Fapemig. Isso se deu pelo fato de que, mesmo diante de várias ações de comunicação empreendidas pela Fundação, não havia um conhecimento sistemático sobre o público-alvo, apenas inferências obtidas por contato esporádico via e-mail, redes sociais, telefone ou pessoalmente. Em pouco mais de três meses, foram coletadas respostas de 1158 participantes, cujo perfil apresentaremos a seguir.

Os participantes do sexo masculino correspondem a $55 \%$, enquanto $45 \%$ se declararam do sexo feminino - resultado que pode ser considerado equilibrado. Quanto à idade, há predominância de um público adulto, composto por $45 \%$ de pessoas entre 19 e 35 anos, seguido de um percentual total de $54 \%$ com mais de 35 anos. 0 público infanto-juvenil e adolescente, com menos de 18 anos, representa cerca de 1\%, um desafio para o projeto, já que há um esforço, explicitado em diretrizes institucionais, para a necessidade de atingir o público em idade pré-universitária.

Quanto à escolaridade, observase a predominância de um público já inserido no meio acadêmico, tendo a maioria dos respondentes títulos de doutorado (35\%) ou especialização/mestrado (32\%). Além desses, outros 17\% afirmaram ter 0 ensino superior completo, reforçando a análise de que o "Projeto Minas faz ciência" é bem disseminado nas instituições de ensino superior (IES). Esse público costuma se informar sobre temas em geral principalmente por meio da internet, em portais de notícias (84\%), sendo a segunda maior fonte de informação as revistas e os jornais impressos (60\%). A televisão foi escolhida por $56 \%$ dos participantes, seguida pelas redes sociais (41\%) e pela conversa com amigos (38\%). 0 rádio vem em último lugar, escolhido por apenas $22 \%$ dos participantes.

Quando o assunto é CT\&I, esses percentuais mudam ligeiramente: os portais de notícia permanecem em primeiro lugar, sendo a escolha de $80 \%$ dos participantes. Em seguida, vêm as revistas e os jornais impressos, com 65\%. Mas a conversa com amigos ganha credibilidade, sendo a fonte de informações indicada por $30 \%$ dos respondentes. Redes sociais são utilizadas apenas por $25 \%$, seguidas pela televisão (24\%) e pelo rádio (6\%).

O cenário permite inferir que o público do projeto reconhece na mídia online e impressa uma fonte confiável de informações sobre os assuntos de ciência e tecnologia, mas, considerando o perfil escolar anteriormente apresentado, também reconhece a importância de trocar informações entre os pares - por isso, a conversa com amigos ocupa a terceira posição como fonte de informação. A comunicação entre pares, a partir de canais informais de interação, vem se ampliando, tendo em vista a intensa presença das tecnologias digitais em rede, que facilitam e ao mesmo tempo demandam, cada vez mais, esse tipo de interação.

O formulário online buscou identificar também hábitos mais gerais de acesso à internet. Tal informação é relevante para ponderar a criação do conteúdo para as mídias móveis, tendo em vista que o público respondente não se enquadra no

7 Disponível em: <https://www.facebook.com/minasfazciencia>. Acesso em 4 jul. 2016

8 Disponível em: <https://twitter.com/minasfazciencia>. Acesso em 4 jul. 2016.

9 Disponível em: <https://www.facebook.com/fapemig>. Acesso em 4 jul. 2016

10 Disponível em: <https://twitter.com/fapemig>. Acesso em 4 jul. 2016. 
perfil dos nativos digitais. Foi identificado, por exemplo, que os participantes da pesquisa utilizam com mais frequência notebooks para ter acesso às informações, e que acessam principalmente da própria casa.

Terminado o primeiro ciclo de perguntas sobre hábitos de consumo de notícias e acesso à informação online, o questionário apresentava questões que visavam à identificação do nível de conhecimento dos participantes da pesquisa sobre o "Projeto Minas faz ciência". A revista, por ser o produto mais antigo, teve o melhor desempenho, sendo conhecida por 843 respondentes. Os demais produtos tiveram números bem abaixo do esperado, sendo o blog conhecido por 324 pessoas, o canal do YouTube Ciência no Ar, por 110 e o podcast Ondas da Ciência, por 91

Outro dado obtido sobre a revista complexifica a relação dos participantes com a fundação: embora cerca de $73 \%$ das pessoas já tivessem ouvido falar dela, menos da metade, $42 \%$, se declara assinante. 0 material é acessado por cerca de $10 \%$ dos respondentes em seus ambientes de trabalho e estudo, demonstrando o potencial multiplicador das instituições que recebem os exemplares da Minas Faz Ciência gratuitamente. Dentre os assinantes, a maioria recebe a revista há mais de 3 anos e pouco mais da metade (53\%) tem o hábito de ler todas as reportagens.

Já com relação ao blog, que concentra não só reportagens escritas sobre os projetos financiados, mas também links diretos para acesso aos demais produtos (podcast e canal no YouTube), ainda é pequeno o número de pessoas que 0 acessam diariamente (2\%) sendo que mais de $70 \%$ dos respondentes nunca acessaram o endereço blog.fapemig.br. Os resultados de acesso ao canal Ciência no Ar e ao podcast Ondas da Ciência foram preocupantes, já que 91\% dos respondentes nunca acessaram os vídeos do YouTube, número que sobe para 93\% no caso dos podcasts.

Esses percentuais demonstram que, embora o público tenha interesse e hábito de acessar informações na internet, 0 blog mantido pela Fapemig e seus produtos online não estão entre os que servem de referência para os respondentes da pesquisa. Essa informação alertou a equipe para a necessidade de ajustar a produção de conteúdo no blog, a fim de atingir esse público que já está habituado ao ambiente onlinee que tem na revista impressa o único produto de acesso consolidado.

O questionário versou, ainda, sobre outras questões referentes ao perfil do público, como cidade de residência, atividade profissional e temáticas de interesse, que não foram objeto de análise nessa primeira etapa. Além disso, os participantes tiveram um espaço aberto para comentários adicionais, de preenchimento opcional, que apontam novas variáveis e que, junto aos dados acima indicados, geram uma análise mais complexa do cenário, a qual ultrapassa os produtos, implicando a fundação como um todo.

\section{ANÁLISE DOS RESULTADOS}

A partir das respostas do questionário online, foi proposta a realização de um workshop com a equipe de comunicação e relações públicas, além de outros membros da Fapemig, incluindo seu presidente em exercício, professor Evaldo Ferreira Vilela. Entre os presentes estavam colaboradores alocados em diferentes setores da fundação, mas que já participavam de discussões acerca do posicionamento estratégico, como representantes do Departamento de Gestão de Pessoas, do Departamento de Avaliação, do Departamento de Informações Técnicas, do Departamento de Relações Empresariais, da Assessoria da Presidência e da Central de Informações da Fapemig. 
A ideia era partir do "Projeto Minas faz ciência" como um elemento estratégico para se fazer cumprir objetivos de transparência e disseminação do conhecimento produzido pela instituição e, assim, analisar em conjunto quem é o público-alvo "idealizado" pela instituição e identificar com quem ela, de fato, interage.

Para tanto, fizemos uma apropriação da técnica do business model canvas (BMC), buscando adequá-la aos nossos interesses. O BMC é uma ferramenta visual inicialmente proposta por Alexander Osterwalder e Yves Pigneur (2010). Pensada para os processos de desenvolvimento de negócios, a ferramenta vem sendo constantemente adaptada e transformada, tendo em vista as potencialidades de seu uso. Um aspecto interessante do BMC é a flexibilidade de sua utilização, podendo ser trabalhados determinados agrupamentos a cada vez (ou conforme a necessidade). No nosso caso, como o público participante era bastante diverso, utilizamos essa ferramenta como um recurso didático para alinhar as distintas percepções do público interno da organização. 0 uso do recurso se mostrou interessante para auxiliar na compreensão do estágio atual da organização e, mais ainda, alinhar as visões da instituição em relação a sua missão, seu valor e seu público.

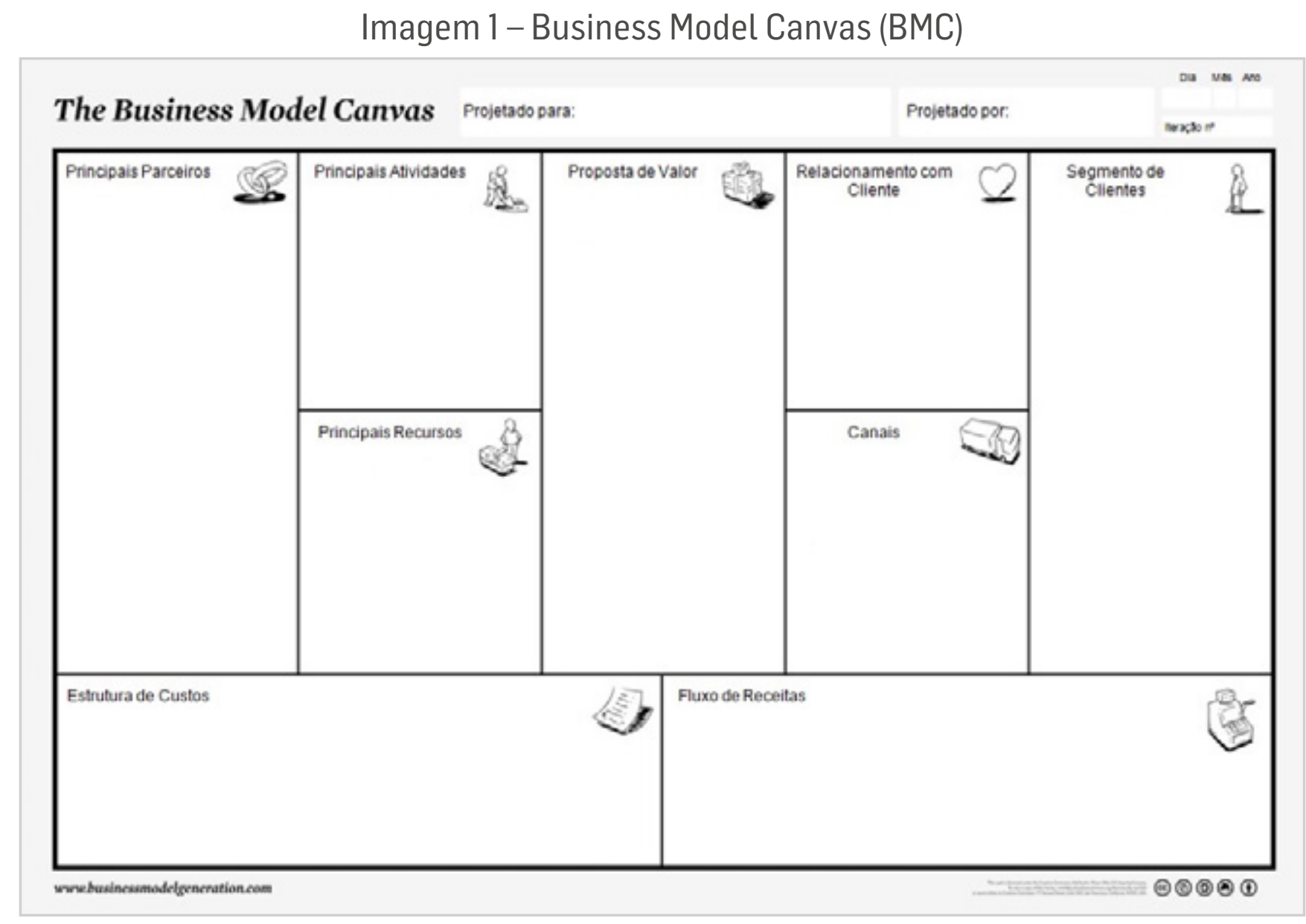

Fonte: www.businessmodelgeneration.com

Conforme pode ser visto na Imagem 1, o BMC se divide em nove quadrantes. Para nossos propósitos focamos nos seguintes: segmento de clientes (público), proposição de valores, relacionamento e canais.

Com foco no público-alvo, esse exercício, realizado nos dias 10 e 31 de março de 2015, permitiu à equipe envolvida perceber certo descompasso entre o público que a Fapemig deseja atingir e o que ela realmente atinge, identificado a partir das respostas do questionário online. Além disso, viu-se que, para o público alcançado a partir dos produtos do "Projeto Minas faz ciência", havia ainda um conjunto importante de ações a ser realizado para melhorar a comunicação.

Assim, a equipe do projeto buscou adequar as estratégias de comunicação, tanto para ampliar o acesso ao público que passou a ser conhecido, quanto para que o conteúdo pudesse chegar a novos e diferentes perfis de pessoas que compõem 0 
chamado público não especializado. Para isso, foram intensificadas ações que visassem à adequação do conteúdo jornalístico aos diferentes meios, ainda que reconheçamos que a ação escapa às nossas intenções.

Os vídeos do canal Ciência no Ar, por exemplo, tiveram sua vinheta reformulada e modernizada, com inserção de música e elementos gráficos que pudessem atrair a atenção de uma parcela mais jovem e pré-universitária. Os podcasts Ondas da Ciência passaram a ser distribuídos na programação de rádios públicas, universitárias e educativas por meio da Rede Ondas da Ciência (ROC), de modo a atingir um perfil de ouvintes do rádio tradicional com drops de informação científica nos intervalos da programação.

No blog Minas Faz Ciência, o objetivo foi atrair a parcela do público que, já conhecendo a revista e acessando a internet em busca de informações sobre CT\&I, pudesse ter nos produtos da Fapemig uma nova fonte de conhecimento sobre a produção científica do estado, partilhando da credibilidade conquistada nos dezesseis anos de existência da revista impressa. Assim, foram intensificadas as postagens de entrevistas e a divulgação de pesquisas financiadas pela fundação de modo que o pesquisador entrevistado não só se sentisse interessado em participar daquele espaço, como também se mobilizasse pela divulgação do link em suas redes sociais.

Assim, o projeto conquistou na internet um público que já era cativo, mas que não tinha por hábito acessar o blog. Vale notar, também, que a própria pesquisa pode ter contribuído para ampliar o conhecimento do público sobre os produtos online, uma vez que mencionava no questionário os endereços e links para visitação. As estratégias adotadas, ainda que bastante pontuais, se mostraram bem-sucedidas, principalmente quando comparados os dados de acesso ao blog nos últimos cinco anos, desde sua criação.

Conforme o gráfico a seguir, 2015 encerrou-se com um recorde de acessos de 25.584 visitantes e 44.366 visualizações, em um total de 161 novos artigos publicados (incluindo aí os posts de divulgação dos vídeos e dos podcasts).

Gráfico 1 - Acessos e visualizações do blog Minas faz ciência, de 2011 a 2015.

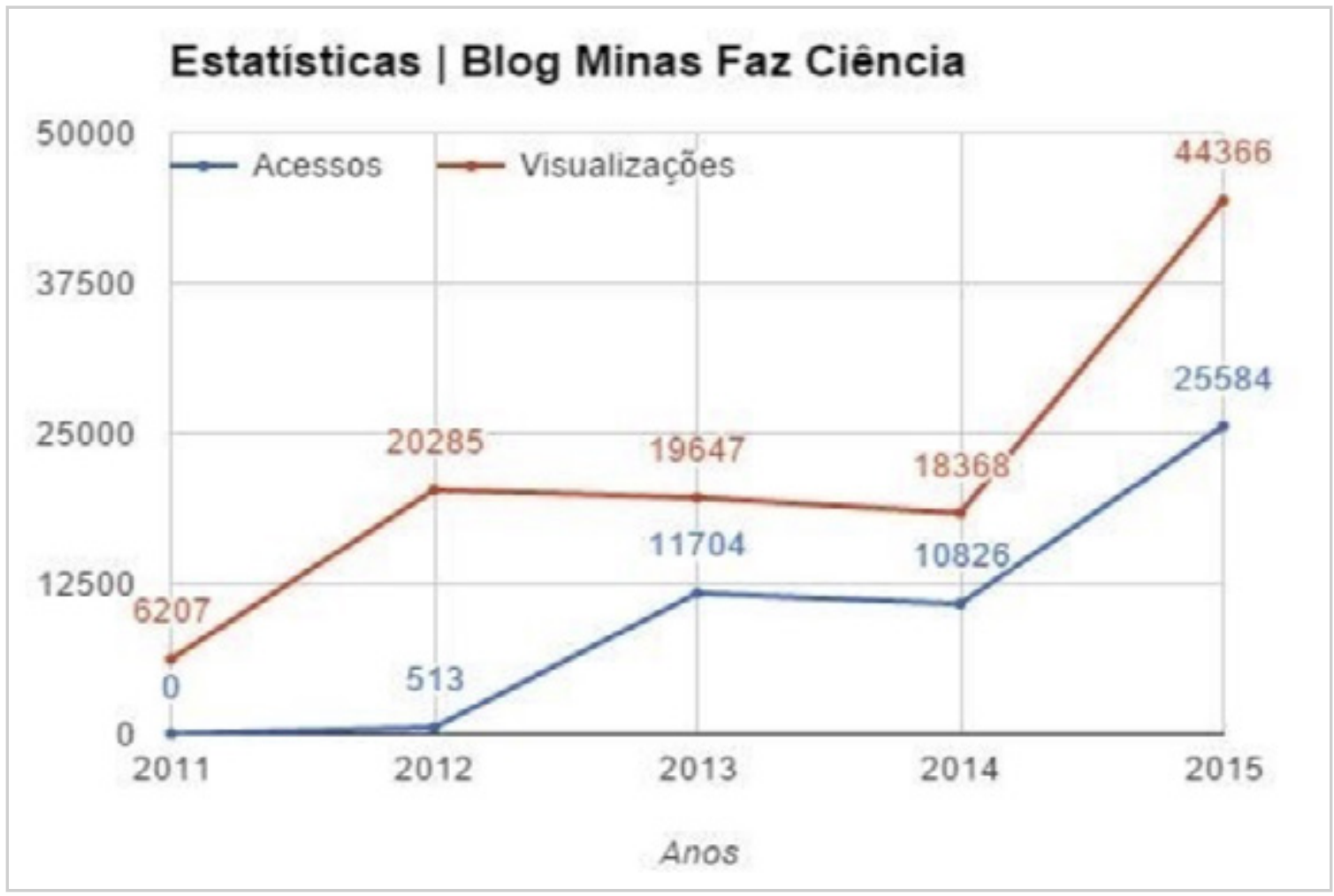

Fonte: Relatório de acessos do sistema Wordpress, em http://blog.fapemig.br/ 


\section{ANO 13 • NÚMERO 25 • 2 SEM. 2016 - ORGANICOM}

DIMENSÕES ESTRATÉGICAS DA COMUNICAÇÃO DA CIÊNCIA

Diante do desafio de ampliar a audiência, concluiu-se que a valorização do perfil já conquistado deve servir para 0 fortalecimento e a manutenção dos produtos existentes, a fim de que não se perca a identificação e a participação do público que já acompanha o projeto. Ao mesmo tempo, ainda é preciso que o "Projeto Minas faz ciência" chegue a outros públicos de interesse da fundação que o sustenta, o que resultou, por exemplo, na publicação, em 2015, de uma edição especial da revista impressa, voltada exclusivamente para o público infanto-juvenil, a Minas Faz Ciência Especial para Crianças. Tal edição especial já era um projeto antigo, mas seguia engavetado por diversas razões institucionais. Os resultados obtidos com a pesquisa e a orientação de fortalecimento de vínculos com o público em idade escolar coincidiram com um momento oportuno para o lançamento da revista.

Dentre as estratégias possíveis de expansão do público, apontam-se possibilidades para uma maior interação com o público pré-universitário por meio de eventos e a ampliação da distribuição da revista em escolas municipais e estaduais. Também as redes sociais podem contribuir para ampliação da base da audiência, ainda que sejam necessários estudos adequados de linguagem e abordagens das temáticas com humor sem que se perca o rigor da divulgação científica.

Por fim, conforme apontado anteriormente, o questionário coletou também respostas abertas que versavam sobre questões referentes à fundação, como pagamento de bolsas, sistemas e sites fora do ar, ou até mesmo sobre o próprio questionário online. Ainda que não tenha sido objeto de aprofundamento neste artigo, as respostas coletadas apresentam-se como uma oportunidade de novas análises a fim de mensurar questões de prestígio e visibilidade da organização, em paralelo a seus esforços de comunicação da produção científica do estado.

\section{CONSIDERAÇÕES FINAIS}

As estratégias de identificação do perfil do público indicaram que havia uma dissonância entre o público que se buscava atingir e o público que, de fato, tinha acesso aos produtos desenvolvidos no âmbito do "Projeto Minas faz ciência" da Fapemig. Tal constatação não deve ser interpretada como um resultado negativo, mas como uma oportunidade de alinhamento de ações, de acordo com as orientações institucionais no contexto da comunicação organizacional.

No complexo cenário contemporâneo em que as tecnologias de informação e a diversidade de canais e estratégias de comunicação podem vir a promover mais instabilidade do que interação, a clareza diante da fraqueza das estratégias pode ser entendida como uma das maiores forças de uma organização.

A necessidade de as organizações se relacionarem com diferentes grupos, principalmente no que diz respeito às estratégias de comunicação organizacional, impulsionam as ações para o estabelecimento de diálogos e entendimentos sobre suas políticas, seus investimentos, benefícios e riscos. Promover ações e desenvolver canais e alternativas que possam contribuir com a interação e a construção de sentidos torna-se, portanto, fundamental para a sobrevivência da fundação e de seus projetos.

Ainda que uma leitura superficial possa levar a crer que a comunicação organizacional deve se ocupar em harmonizar expectativas e promover a simetria entre perspectivas, promovendo uma homogeneização das diferenças, ao adotarmos a perspectiva da complexidade instaura-se um processo cíclico. As ações comunicacionais se inscrevem em uma dinâmica constante de organização, desorganização, desgaste e reorganização, que demandam, por sua vez, atenção e planejamento constante por parte dos gestores comunicacionais. 
Mais que estabilizar o entendimento do que sejam o público e suas demandas em relação à organização, 0 exercício aqui proposto indica a necessidade de uma reavaliação constante de seus pressupostos de ação com vista a atingir seus objetivos estratégicos.

A comunicação está em contínuo processo de mudança, assim como as organizações e suas atividades. Devemos nos indagar, portanto, frente a tais mudanças de ordem tecnológica, cultural, política e econômica, quais sentidos assumem as práticas da comunicação organizacional diante de seus diversos interlocutores.

\section{REFERÊNCIAS}

BALDISSERA, Rudimar. Comunicação organizacional na perspectiva da complexidade. Organicom - Revista Brasileira de Comunicação Organizacional e Relações Públicas, a. 6, n. 10/11, p. 115-120, 2009.

ESCOSTEGUY, Ana Carolina. Circuitos de cultura/circuitos de comunicação: um protocolo analítico de integração da produção e da recepção. Comunicação, Mídia e Consumo, São Paulo, v..4, n. 11, p.115135, nov. 2007.

FREIRE, Karine. Reflexões sobre o conceito de design de experiências. Strategic Design Research Journal, v. 2 n. 1, jan. jun. 2009. Disponível em: <http://www.researchgate.net/publication/250313338_Reflexes_sobre_0_conceito_de_desig n_de_ experincias> . Acesso em: 2 de jun. 2015

LEWENSTEIN, Bruce V. Models of public understanding: the politics of public engagement. ArtefaCToS, v. 3, n. 1, dez. 2010, p. 1329. Disponível em: <https://ecommons.cornell.edu/handle/1813/37363>. Acesso em: 4 jul. 2016.

MANOVICH, Lev. The poetics of augmented space. Visual Communication. v. 5 n. 2, p. 219240, jun. 2006.

MORIN, Edgar. Introdução ao pensamento complexo. Porto Alegre: Sulina, 2011.

OSTERWALDER, A., PIGNEUR, Y. Inovação em Modelos de Negócios: Business Model Generation. Alta Books, 2011, 300p.

Artigo recebido em 10.08.2016 e aprovado em 04.11.2016. 